\title{
A STUDY OF THE EFFECTS OF LIQUID MUSTARD GAS UPON THE EYES OF RABBITS AND OF CERTAIN METHODS OF TREATMENT
}

BY

\author{
Wing Commander P. C. Livingston, O.B.E., F.R.C.S.E. \\ and
}

Flight Lieutekant H. M. Walker, M.D.

THIS work was undertaken with a view to following, step by step, the damage caused to the eyes of mature rabbits by single drops of liquid mustard, and to attempt to evaluate certain methods of treatment. Therefore, when a typical clinical picture of the effect of mustard was obtained and fresh in our minds, attention was directed to the examination and estimation of various methods of preventing or mitigating the graver changes in the eyes.

As is well known, liquid mustard gas acts upon living tissues as a profound chemical irritant; but it appears that even after the immediate potency has subsided, the evil that is wrought lives on in the shape of highly toxic by-products of disintegration. Whereas damage caused by other powerful chemical substances tends to be localised, mustard exercises not only the primary effect but, in a delayed state, it appears to throw forward from cell to cell a destructive activity that knows no calculable bounds. The observations that we have been able to make have convinced us that there is some degree of natural resistance to this violent chemical-at least in the case of rabbits. In a period of seven days we have witnessed eyes totally destroyed, and others, similarly treated, revealing considerably less manifestations of injury.

Twenty-three mature rabbits were used and their average weight was $2 \frac{3}{4} \mathrm{kgms}$. ; of these fourteen were female. Regarding colour, thirteen were brindle, five white, two black, two gray and one gray-white. The question of colour in relation to resistance is probably not so important as was at first believed, but of all the rabbits, that which was found most gravely affected, was a white rabbit with almost albino eyes.

\section{Technique}

Exposure of the eyes to liquid mustard was effected by applying the smallest possible drop (the maximum size was 0.75 c.mm.) from a fine glass pipette to a point selected between 11 and 1 o'clock on the corneal surface, about $2 \mathrm{mms}$. below the limbus. The eyes were retained open for one minute, and the third lid was controlled by forceps, so that the drop could exercise a 
standard effect without admixture with an unknown quantity of tears. The reaction of the tears of a rabbit are alkaline with a $\mathrm{pH} 8.0$. The same sample of mustard was used throughout the whole series.

\section{Solutions and Substances Used}

In the first instance it was decided to examine the effect of irrigating the eyes with various solutions, and of instilling certain substances.

The solutions for irrigation subjected to test were, bleach powder B.P. $1: 400, \mathrm{pH} 10 \cdot 0$, sodium bicarbonate 2 per cent., pH $8 \cdot 0$, saline 1.4 per cent., $\mathrm{pH} 68$; Bonnefon's solution (a saturated solution of sodium sulphate 800 grams and sugar syrup 200 grams), $\mathrm{pH} 7 \cdot 0$. Substances used for instillation were cod liver oil B.P.; liquid paraffin B.P.; benzoyl peroxide; Oil No. 1 (liquid paraffin with added vitamin A 12,000 units and vitamin D 2,000 units per ml.); Oil No. 2 (arachis oil); Oil No. 3 (cod liver oil with added vitamin A 12,000 units and vitamin D 2,000 units per ml.).

A $1: 10,000$ solution of merthiolate (Eli Lilly) either alone, or with the addition of diffusing factor, was used for its antiseptic effect upon secondary infections. Examination of exudates from swollen and inflamed membrane, however, showed that there was little bacterial infection. The diffusing factor, a substance present in certain tissue extracts, has been shown to have the power of reducing the intercellular barrier, and it was used to ascertain if deeper penetration of the irrigation could be obtained.

It is important here to discuss briefly one or two facts relating to bleach solution B.P. and hydrogen peroxide. In view of the knowledge that in the earliest stages of contamination bleach exercises a retarding influence upon the skin lesions caused by mustard, some experiments were conducted prior to the present study, with various strengths of bleach solution. These experiments consisted of filling the conjunctival sacs of undamaged eyes of rabbits with solutions of bleach in strengths varying from $1: 1,000$ to $1: 50$. It was only when the strength reached $1: 250$ that transient blepharitis and conjunctivitis occurred on the following day. Observations were then made of the effect of these solutions upon corneae scarified with a needle. No material differences were noted between the first and second groups. This encouraged the view that bleach solution $1: 400 \mathrm{might}$, with value, be included for test in the present study. When, however, the technique was changed from a simple pool filling of the conjunctival sac for fifteen minutes, to the projection of the solution upon the cornea through a pipette with the containing flask placed a 
foot above the eye, the picture altered. The cornea became clouded and dry, presenting an appearance much like ground glass. The period of lavage was kept at five minutes, and the changes became noticeable in two minutes. These changes occurred in eyes exposed to liquid mustard, and in eyes used as controls. Partly on this account, and because the most serious case was that of a bleach treated rabbit (No. 1) the procedure lost favour.

Experiments similar to those previous experiments with bleach were carried out with hydrogen peroxide, strengths 0.6 per cent., 0.9 per cent. and 1.5 per cent. The merits of this substance were examined since oxidising agents should convert mustard into the non-toxic sulphoxide. Here again the effect upon the corneae was very marked and there was intense oedema of the conjunctivae. Whether this adverse effect is peculiar to rabbits is not known. An instance has been recorded in which the anterior chamber of a patient suffering from hypopyon was irrigated with hydrogen peroxide and the eye saved. Hydrogen peroxide was not used in the present experiments, but a substitute, benzoyl peroxide in oily solution, was tried on the grounds that its liberation of oxygen is less rapid. However, as will be seen, the results from its use were not so good as those obtained from other procedures.

In the irrigation of the eyes during these experiments the greatest care was exercised to ensure that the lotions reached all spaces in the conjunctival folds and the areas in front of and beneath the third lid. The initial irrigations (that is, those given shortly following the application of mustard) were carried out for a period of five minutes, while later irrigations (those given during treatment) were carried out for half a minute. In the instillation of the oil substances, eight drops were given at each application. The merthiolate solutions were run into the eyes through a glass pipette-about 4 c.c. at a time, the lids and conjunctivae having been previously well cleaned with water.

When we had made the preliminary observations and had become familiar with the reactions of the eye to mustard, there were several points that seemed to be significant and to suggest that there might be yet another method of approach to the subject of treatment.

The differentiation made later (see page 77 ) between a first stage of focal involvement and a second of spread, must be taken into account in the consideration of treatment. During the stage of spread a deep keratitic change occurs throughout the substance of the cornea ; once this stage has started it is obviously impossible noticeably to affect its progress by surface applications. 
The observation that rabbits showed some varying degree of natural resistance, sometimes fairly strong, to the effect of mustard, seemed to indicate that if we were to mitigate or prevent the stage of spread, we must attempt to increase the natural resistance; and that the only profitable method of approach was through the blood stream. Only in this manner could the deeper tissues affected in the changes be reached. The progressive. lesions of the cornea are unlikely to be due to long persistence of mustard as such in the tissues. It has been suggested that mustard, by combination with the free amino groups of the protein molecule, can form a stable toxic substance.

If then, the corneal lesion of mustard is brought about by a fundamental alteration in the biochemical structure of corneal tissue through a chemical action or interaction, the barrier against this can only be the administration through the blood stream of some substance that might inhibit the interaction.

In view of the degree of natural resistance shown by some animals, it was considered desirable first to investigate the possibility of inhibiting or preventing the stage of spread by the administration of a substance, ascorbic acid, that is normally present in the lens and cornea in high concentration. Ascorbic acid* is a substance belonging to a group known as " redox potentials," which maintains a fine balance between the processes of reduction and oxidation by acting, either as a reducing or oxidising agent, whichever action is called for. From a chemical point of view, therefore, it seemed that ascorbic acid might be capable of preventing the interaction between mustard and the corneal tissue which leads to the spreading keratitic change in the cornea. From the medical viewpoint ascorbic acid is non-toxic and can be given in very large amounts, the only limitation being that of cost. Four rabbits were given doses of $500 \mathrm{mgms}$. intravenously, and the result of the experiment was of such outstanding interest that it opens up a considerable field for further investigation of the treatment of this type of injury.

\section{Clinical Examinations}

With the exception of four mornings, daily observations with the loupe and lens were carried on for twenty-eight days. Detailed

* Ascorbic acid (vitamin C) is prepared synthetically, occurs in minute colourless crystals and is readily soluble in water. It is stable in the solid form when kept in sealed glass bottles. A 10 per cent. solution can be prepared for intravenous injection and can be sterilised by filtration; it must not be boiled. The solution remains stable only when kept in the dark, under nitrogen, or with the addition of an antoxidant, such as sodium sulphite in a strength of 0.2 per cent. There is no known toxicity of ascorbic acid, and very large doses can be given if required. Ampoules of ascorbic acid in various strengths can be obtained. Saturation can be ensured by an intravenous dosage of $1,000 \mathrm{mg}$. lst day, $500 \mathrm{mg}$. 2nd day, $200 \mathrm{mg}$. 3rd day and $100 \mathrm{mg}$. 4th and 5 th days. 
shorthand notes were taken on each occasion. In this way it was possible to record the state of closure of the lids, sensitivity to light, quantity and quality of discharges, progress of lid scarring, keratitic changes and involvement of the iris. In addition, direct smears and cultures were made, photographs taken, and sections cut for recording histopathological changes.

\section{Clinical Features of Mustard Drop Contamination}

With the lids open and well controlled and the third lid restricted by forceps, a drop of the liquid mustard was placed upon the cornea about $2 \mathrm{mms}$. from the limbus and at a position corresponding to between 11 and 1 o'clock. The eyes were kept open for one minute. Observation through the loupe of the behaviour of the drop showed that for five to ten seconds there is no noticeable activity. It remained as an oily globule bounded by a sharp rim of demarcation. A small break in the tissue surface then allows the drop to throw out a projection which, in turn, is arrested while another starts out from a fresh angle. This movement, pause and new movement, continues until the globule has assumed a somewhat starlike shape. During this process, it seems that the drop is having its effect in a downward direction also, because after a lapse of five minutes, the cornea is found to stain with fluorescein deeply over the area invaded.

The local damage, which consists of destruction of the cells of the corneal epithelium down to and apparently including Bowman's membrane, is almost immediate; and it is felt that no form of counter attack can retard the damage at this stage. The chemical interaction between liquid mustard and the tissues of the eye is remarkably strong and rapid. In order to examine this interaction a drop of the liquid was placed at the usual area on the right cornea of a control rabbit (No. 18) and the eye allowed to close and remain untreated for fifteen minutes. Thereafter, the conjunctival folds, lid angles and corneal surface, were stroked with a platinum loop, and the secretions collected and transferred to the left eye. No inflammatory or other changes were seen in this eye and the inspections were stopped after 96 hours. The right eye, however, revealed keratitic and lid changes.

The ocular damage in rabbits is of a type that follows a fairly regular course. This description applies not only to cases left without any kind of treatment, but also to those of a fairly large group which, a few minutes after the application of mustard, received a lavage for five minutes. First there appears the area of staining already noted, with its sharp edges and deep green coloured base. After a lapse of ten to fifteen minutes there is a 
tendency to close the eye in presence of strong light. There now appears a fine corneal haze which surrounds the central point of injury. The superficial epithelium shows fine linear striae, which later combine by transverse bars until a cobweb effect results. After 24 hours there is usually a great change in the picture. The primary area continues to stain, although often its extent is not much increased. There is now dense corneal oedema, the fine cobweb effect being masked by changes further below the surface, and the area of damage now staining may equal four to five times the primary seat of injury. A mucoid discharge, becoming whitish and thick later, makes its appearance and there is often blistering of the conjunctival folds. In about one-third of the cases the iris will have contracted. After 48 hours the corneal damage in the form of deep keratitis may prevent a thorough examination of the size of the pupil or the iris pattern. After four days the discharges are usually sufficiently intense to cause

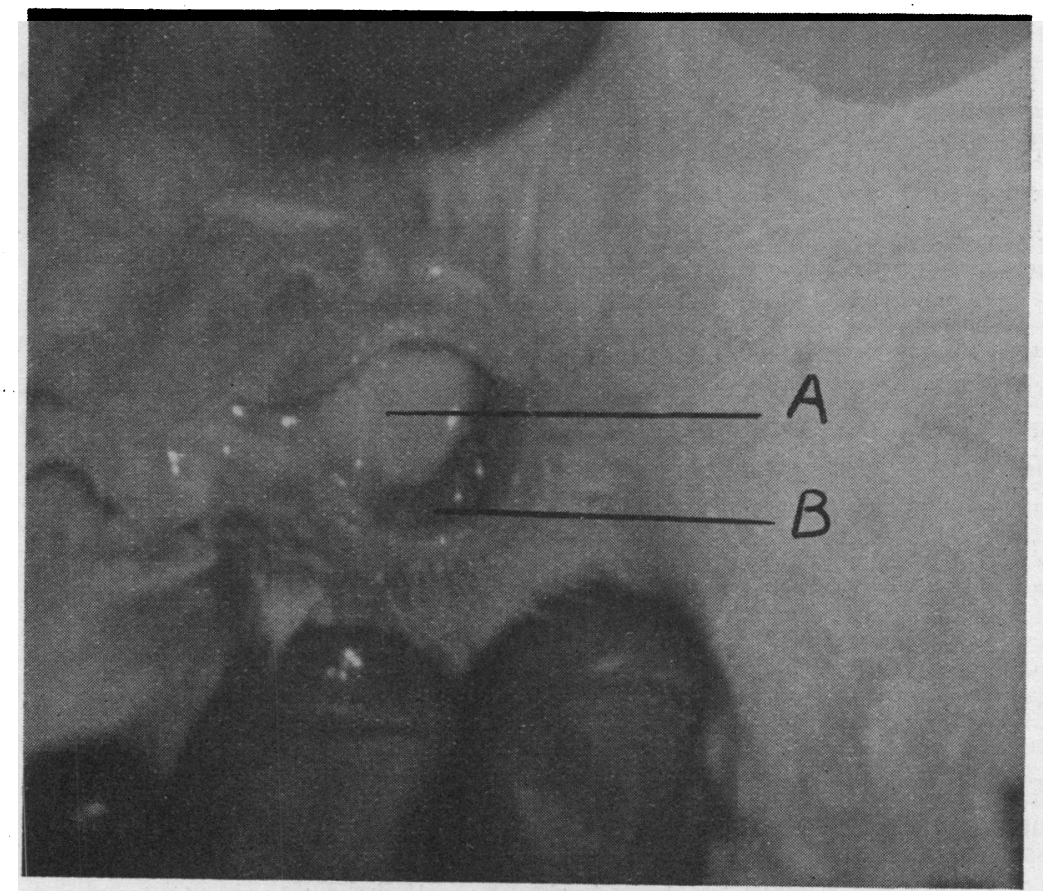

RABBIT No. 1 (Observation Group).

Left eye photographed on the 12 th day, after 4 days treatment with merthiolate $1: 10,000$ showing very acute involvement with massive leucoma and staphyloma $(a)$ and oedema of the conjunctiva (b).

Note.-The white areas in these illustrations are caused by the reflection of the photographic lamp. 
firm adherence of the lids. There are thick crusts on the outside and much muco-pus within. The cornea, however, although greatly involved by keratitic changes, does not stain readily. Where staining occurs, it is very fine and of a branching character. At this stage the iris has in most cases resumed its normal shape and size, and from examination of the iris pattern in cases in which constriction was a characteristic feature, it seems that this process is due more to the stimulus of irritation than to exudative or other changes. It is now that the lid damage becomes apparent, and ectropion appears in the worst cases, together with serious contraction and often a membranous condition such as is seen in diphtheritic conjunctivitis. The lid scarring tends to be linear, and extends from the lid margins backwards and into the deeper conjunctival folds, so that the margins seem as if notched in three or four places. In contra-distinction to this picture, there may be instances in which there is an attempt at spontaneous recovery aided possibly by the simple use of water-washings. Where the damage is intense, the process may advance to a general disintegration of the whole corneal substance with development of large leucomata or staphylomata, as observed in rabbit No. 1.

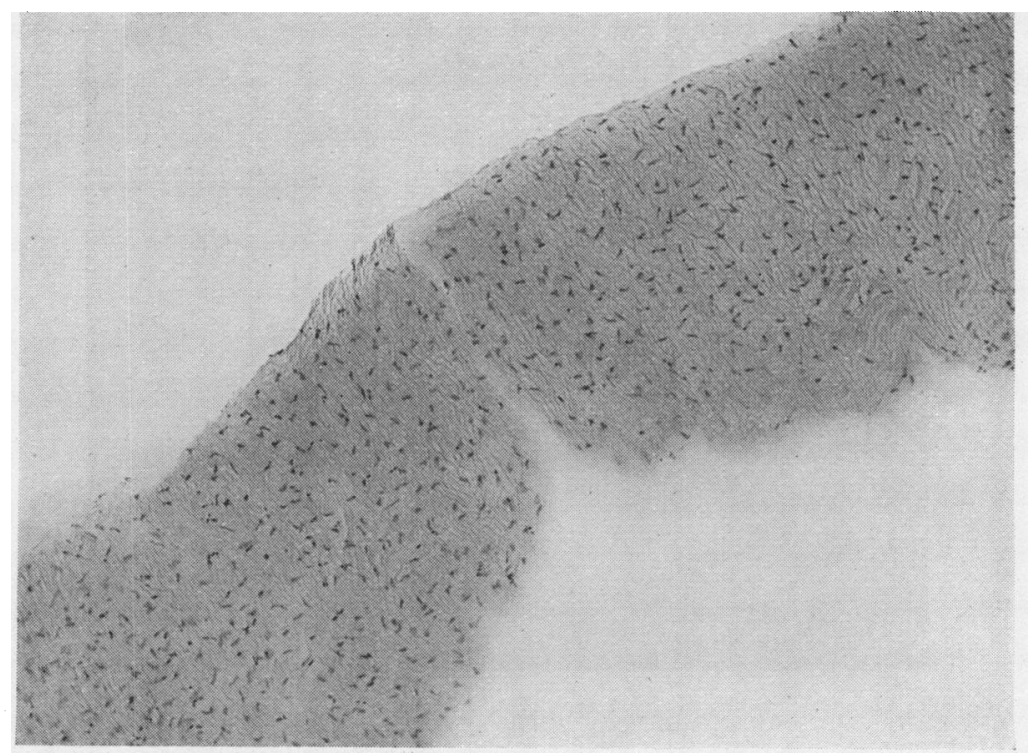

Right Eye of RaBbit No. 12

Showing extensive corneal damage. There is desquamation of surface epithelium and endothelium on Descemet's membrane.' A perforation is present, which is partially filled with exudate. For general report see page 87 . 
The foregoing represents a digest from a large volume of case notes taken while watching the progress, uncontrolled except as previously noted, of the tissue reactions to the influence of a drop of liquid mustard.

The experiments themselves were divided into three groups, according to the course of treatment adopted namely, the observation group of nine rabbits; the treatment group of nine rabbits; and the ascorbic acid treatment group of five rabbits.

\section{The Observation Group}

The principal object here was to examine the effect of a drop of mustard oil in eyes receiving one lavage five or fifteen minutes after exposure, and in other eyes not receiving lavage. Table No. I indicates the technique adopted and gives a brief summary of the end results. The group was kept under observation for

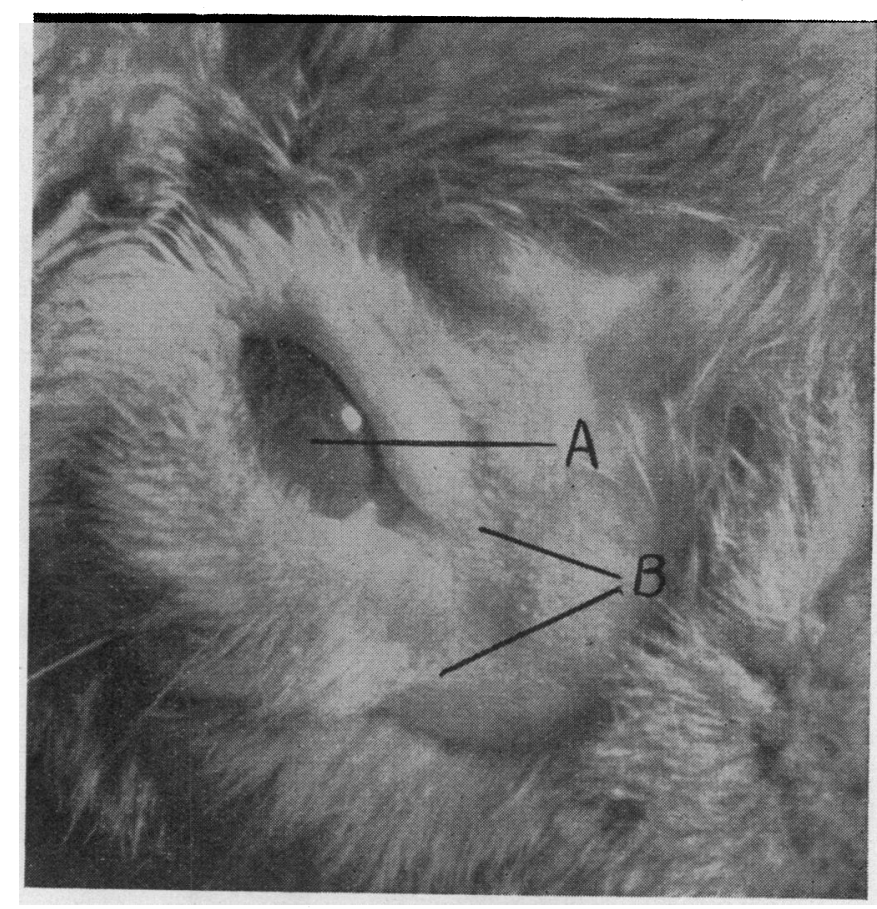

RABBIT No. 2 (Observation Group).

Right eye photographed on the 25 th day, 8 days after the cessation of treatment with merthiolate $1: 10,000$, and cod liver oil, showing a horse-shoe shaped staining area $(a)$ within which keratitic changes of a non-staining type have taken place. Upper and lower lids appear almost normal. The loss of hair $(b)$ due to early discharges is a characteristic feature. 
seven days, after which time an attempt was made to cure the more serious features by using merthiolate $1: 10,000$ (with or without diffusing factor) and cod liver oil. Considering the inflammatory states to be dealt with, the results of this treatment

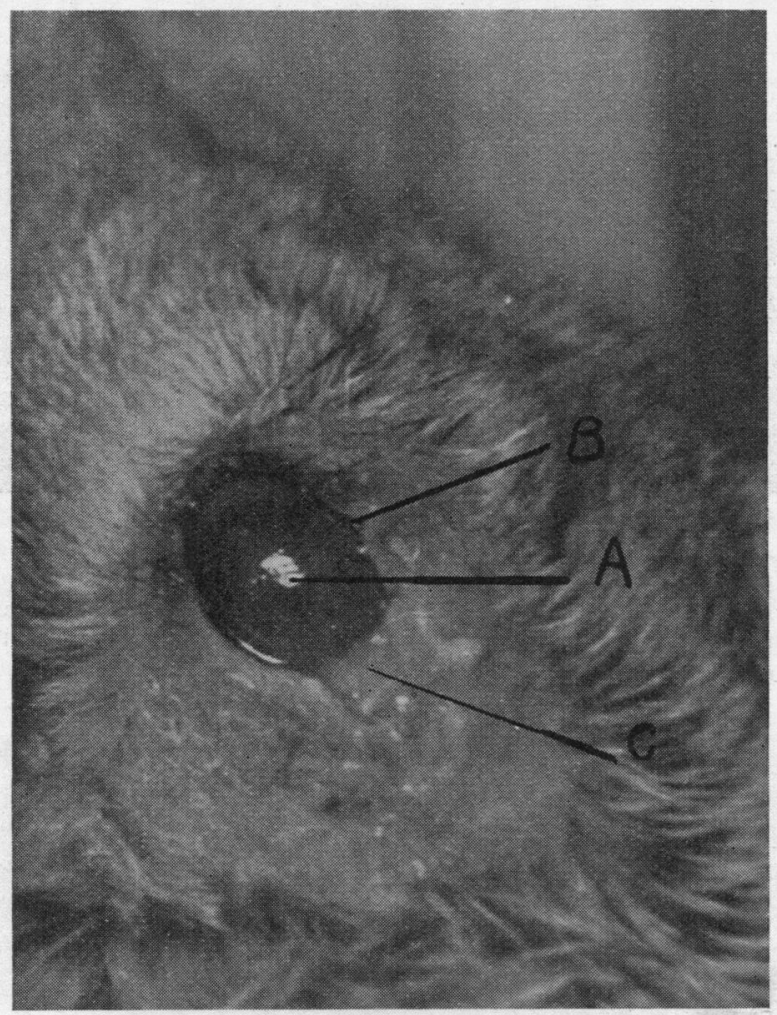

RABBIT No. 3 (Observation Group).

Right eye photographed on 11 th day, after 5 days treatment with merthiolate 1:10,000 showing corneal changes, loss of regular light reflex on the surface $(a)$. Typical lid scarring with its V-shaped contraction is shown above $(b)$, while scarring of the third lid (c) and mucoid discharges are present.

were extremely satisfactory. The addition of diffusing factor to the merthiolate appeared to have an advantage.

Particulars of one experiment might be noted here. Rabbit No. 4 which offered such a remarkable resistance as a control, was exposed a second time, being treated with cod liver oil (8 drops) in the right eye and liquid paraffin ( 8 drops) in the left eye five minutes before the application of mustard. This experiment was made with a view to discovering whether, in a case of 


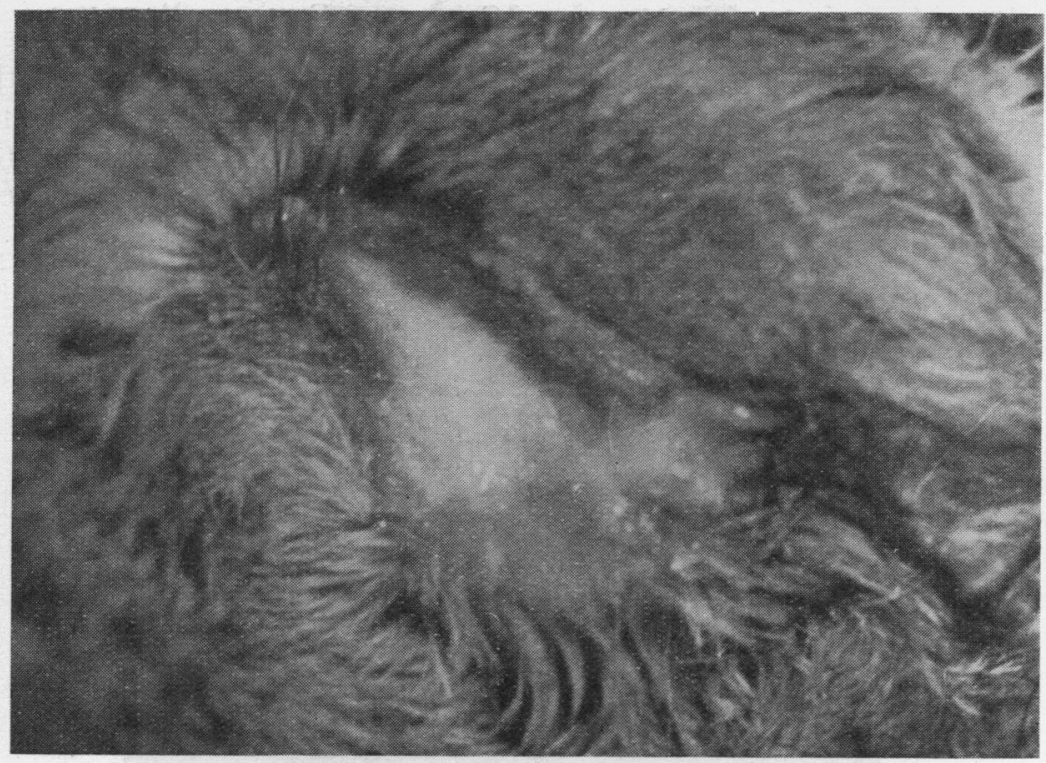

RabBit No. 3 (Observation Group).

Left eye photographed on the 11th day, after 5 days treatment with merthiolate $1: 10,000$, showing the severe muco-purulent discharge that occurs in some cases, characterised for the most part by its extreme whiteness.

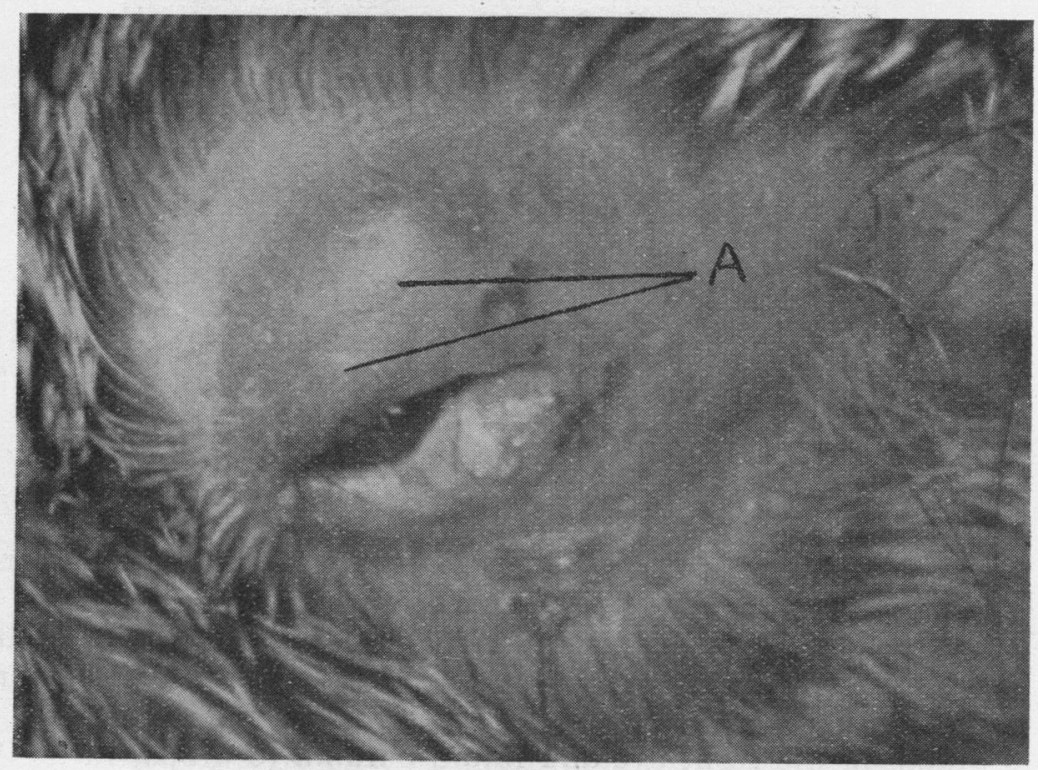

RaBBIT No. 6 (Observation Group).

Right eye photographed on the 20th day, after 14 days treatment with merthiolate $1: 10,000$ and cod liver oil. This case demonstrates the marked thickening of the upper lid $(a)$ which remained swollen tense and deeply infiltrated, while the lower lid shows a characteristic ectropion. 
known resistance, an oily film would give any useful prophylaxis. Whether or not the initial resistance had been lowered by the first experiment, cannot be defined, but the reactions exhibited in the second experiment suggested that the presence of oil tended to spread out the effect of the mustard. After 24 hours there was in the right eye " a diffuse, fine, keratitic haze over most of the cornea," while in the left eye " the oedema was definitely greater than in the right eye, and the cornea was hazy with a condition just as serious as found in cases untreated." Water washes and continuation of cod liver oil treatment cleared the right eye in fifteen days. At that time, the left eye still showed keratitis, scar tissue was extensive, but the lids were free from active signs.

\section{The Treatment Group}

The purpose of this group was to estimate the value of various methods of treatment of the eyes after exposure to mustard. The group consisted of nine rabbits, one black, four brindle, three white and one gray-white. Table. No. II indicates the line of treatment adopted in each case. Treatment was carried out twice daily, and in order to maintain a proper balance, irrigations subsequent to the initial five-minutes lavage, consisted of simple washing out for about half a minute. Oily drops were used liberally, usually eight being counted.

In examining the features of experimental injury caused by a drop of mustard oil there are three stages to be considered :

(1) The stage of immediate focal involvement.-As a point at which to check the havoc caused by mustard, this stage must be dismissed. The direct contact of the corneal epithelium with this substance which possesses such profound toxicity, must certainly kill the adjacent cells, and having killed them, by its permeation must kill further cells and structures in its close vicinity. From a practical standpoint it is impossible to hope to receive a soldier or civilian for treatment within five minutes of contamination. By that time the first damage has been done.

(2) The stage of spread.-Treatment here becomes a matter of limiting the wave of secondary keratitis which, by its manner of fine cobweb infiltration, moves forward and downward in an increasing circle of attack. Against this there is, first, the varying degree of natural resistance well shown in the observation group of experiments. How much this applies to humans it is difficult to say, but that it exists in some degree would appear certain when consideration is given to the general experiences of clinical ophthalmology. For example, a phlyctenular conjunctivitis or keratitis may respond quickly in one case, while in another receiving the same treatment, it may drag on for weeks or 
even months. Of the many cases of mustard gas eye injury during the Great War a large proportion recovered with apparently no lasting harm, while some remained permanently damaged and yet others, showing a transient period clear from features, developed gas keratitis in anything from ten to sixteen or more years after known exposure. Secondly, there is the principle of using cod liver oil, which is known to assist healing, to fortify the corneal structure, and raise some kind of barrier against the intensely active by-products resulting from neighbouring cell destruction. So far as the eye is concerned, how much this property of cod liver oil is due to the vitamin A content, how much to other contents of the oil, such as the peroxidases, and how much to the mechanical protective coating, cannot be assessed; but it is strongly indicative (as shown in the case of rabbit No. 4) that cod liver oil possesses some quality not held by a mineral oil. Furthermore, in concluding the study of the observation group (from the seventh day onward) it was shown that advanced damage responded well when cod liver oil formed part of the treatment. In several cases keratitis was checked and the corneae began to clear. It was only in such destructive involvement as occurred in rabbit No. 1 that the conditions leading to blindness resisted treatment. The choice of a specific oil remains open, but cod liver oil is easily obtainable, with or without added vitamin $A$ and requires no sterilization.

(3) The stage of secondary infection.-From examination of smears taken from discharges of eyes showing particularly severe reactions, it was found that there was a high proportion of cellular debris with comparatively few bacterial cells. Between the fifth and eighth days smears from seven rabbits showed, " a few Gram positive, short, fine bacilli, a few short diplo-bacilli, a few Gram positive cocci." Therefore, the profuse discharges were more in the nature of massive desquamations than of bacterially charged pus. However, it is recognised that mustard infection in the human eye would probably invoke active corneal ulceration and much and varied bacteriological flora. Although the smear count in the rabbits was relatively low, the use of merthiolate, especially with added diffusing factor, helped very definitely to clear up the condition, and when used in conjunction with cod liver oil, helped to advance resolution. It was considered that the optimum period of value for antiseptics was between five and seven days. Their continued use after seven days, showed in one or two cases indications of returning congestion as if the best purpose of the antiseptic had been served.

Concerning the diffusing factor, it must be understood that for practical purposes this substance is still in the experimental stage; 
it has been used as an interesting addition in this study rather than with the object of suggesting its incorporation in lotions. There is one point of possible interest regarding the clinical appearance of eyes treated with diffusing factor. It was found that there appeared a tendency for the development of fine vascularisation at the corneo-scleral margin. The number of cases is, of course, too small to lay down any ruling. If it should be proved that late gas keratitis in man is the result of a vascular handicap caused by the destructive influences at work at the time of the primary lesion, it would seem beneficial if such a thing were possible to encourage the formation of new vessels.

It appeared that during the stage of inflammatory reaction and secondary infection, advantage could be gained if some method were devised by which intimate contact could be maintained between lotions and tissue folds. Particularly would this apply to man where frequently, owing to oedema, slippiness of lids and blepharospasm, it is impossible to apply any treatment to more than a very limited area. From this arose the design of a special irrigating speculum later to be described.

Following are extracts from the progress notes of the nine rabbits in the treatment group :-

Rabbit No. 10.- The right eye, after ten minutes, showed fine corneal opacities and linear striae, with staining of one-third of the corneal surface. After 24 hours staining was much reduced, and after 48 hours the animal did not appear to have suffered any inconvenience. The corneal structure was only faintly hazy. On the third day treatment was stopped and there was no discharge, no conjunctivitis, and only very fine marking on the third lid.

The left eye stained over the centre of the cornea and a fine $\mathrm{V}$-shaped scratch was noted. It was considered that this must have been due to the eye having been touched with the pipette as the mustard was applied. Lavage with Bonnefon's solution This seemed to cause more discomfort than lavage with other lotions. After 24 hours the eye was one-quarter open and the conjunctiva was severely inflamed. After 48 hours the eye was half open and there was some watery discharge. There was greater sensitivity to light than in the case of the right eye. The cornea showed a localised opacity; the iris was clear. After five days the discharge was very slight and there was no lid scarring; and on the seventh day the cornea was clearing rapidly. On the fourteenth day treatment was stopped as the condition was " very satisfactory with the eye wide open and free from discharge and the cornea almost clear." In view of the fact that this eye was exposed for more than twice the period of exposure of the right eye before the initial lavage, the end result can be considered very promising. 


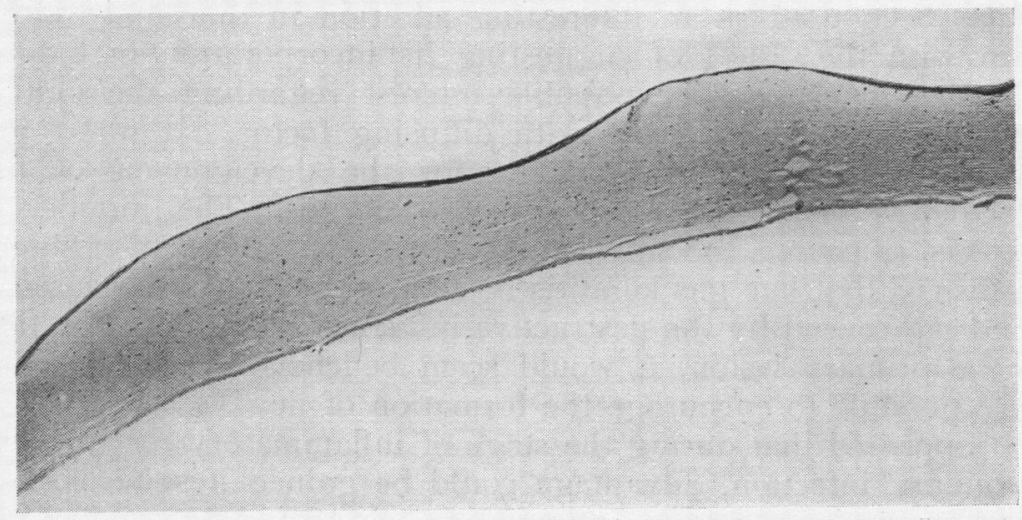

RABBIT No. 11.

Photomicrograph of the left cornea- $\times 45$. Showing marked irregularity due to swelling and oedema of the substantia propria of the cornea.

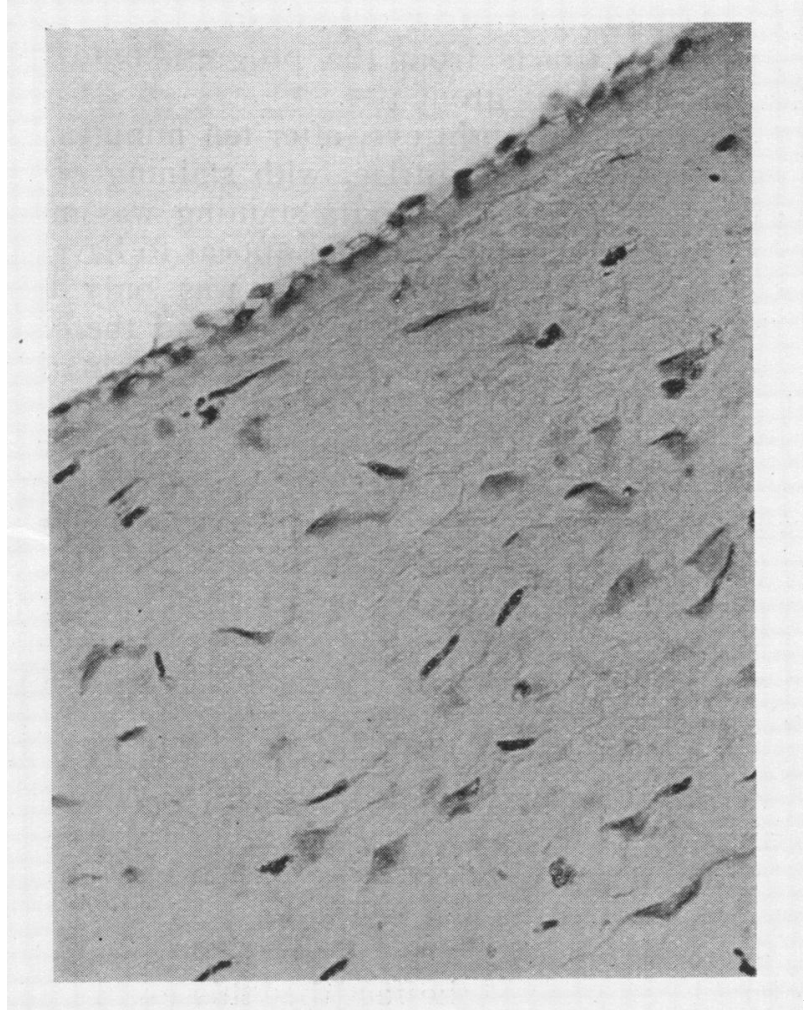

RABBIT No. 12.

Photomicrograph of the right cornea $-\times 350$. Showing fragmentation of the corneal corpuscles, presence of eosinophils, and swelling of endothelium on Descemet's membrane. 
Rabbit No. 11. - The right eye had rather a large deposit of mustard which tended to run inwards. After 24 hours there was severe conjunctivitis, blepharitis and oedema of the cornea. After 48 hours the eye was matted with muco-pus; the cornea was hazy and stained in the centre, and the third lid showed contraction. After four days mucopurulent discharge glued the lids; the cornea was hazy and the iris difficult to see. On the sixth day there was dense opacity of the cornea and marked scarring of the upper lid. Merthiolate with diffusing factor was added to the treatment on the tenth day. The discharge diminished rapidly, and had almost disappeared by the seventeenth day. The cornea, however, was " milky white with a bluish tinge, the whole having the appearance of a fine section of a sea-shell." Vascularisation was present in a fine capillary network. The keratitic changes showed as concentric rings. Ectropion was marked.

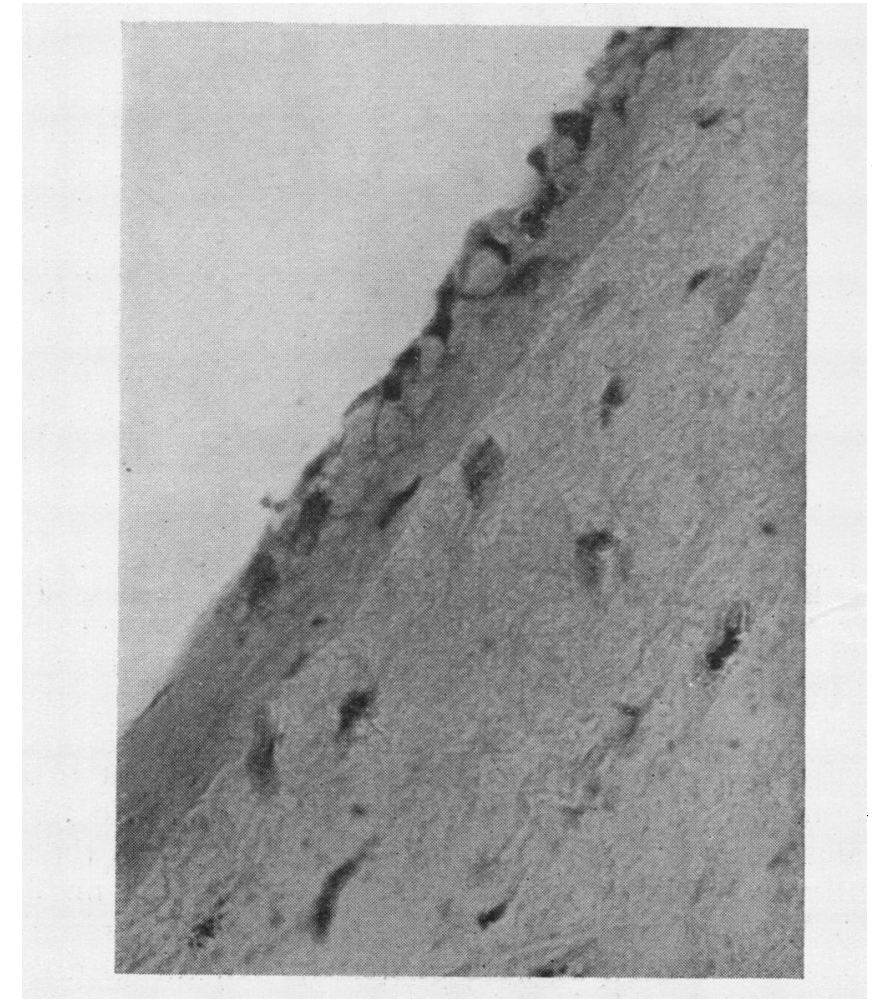

RABBIT No. 12.

Photomicrograph of the corneal substance of the right eye $-\times 500$. Endothelium on Descemet's membrane, showing swelling and vacuolation, with partial desquamation. 
The left eye within 48 hours showed very definite blistering of the upper lid, mucopurulent discharge and deep keratitis. In three days the lids were firmly stuck. There was oedema of lids with contraction; and dense corneal opacity. In view of the marked reactions, the benzoyl peroxide treatment in this case was withdrawn and substituted by merthiolate with diffusing factor and cod liver oil. By the thirteenth day the cornea looked almost clear and light was well tolerated. However, lid contractions and

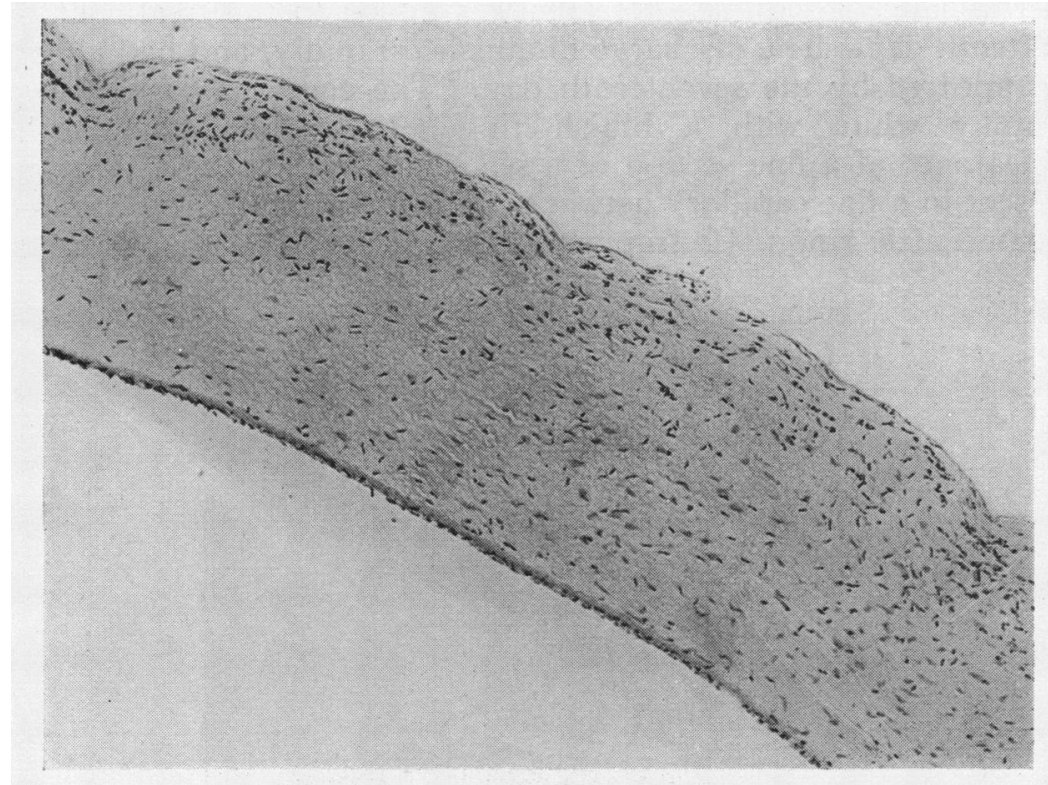

RABBIT No. 12.

Photomicrograph of the cornea of the right eye $-\times 110$. Showing irregularity of cornea, loss of epithelium, cloudy swelling of lamellae, infiltration by eosinophils, fragmentation of corneal corpuscles, and some desquamation of endothelium.

a mucoid discharge persisted. The animal was destroyed on the seventeenth day and the eyes kept for examination.

Rabbit No. 13.- - Here it was considered of interest to extend the duration of mustard attack. The drop applied to the right eye was slightly larger than usual. Within 24 hours the cornea was slightly hazy, but not markedly so; there was no definite staining. After 48 hours there was seen a fine keratitic haze which stained, and the lids were blistered. On the fifth day the cornea still stained and the iris pattern was not clear. On the ninth day merthiolate with diffusing factor was substituted for the saline washout. On the sixteenth day there was "very slight blepharitis and a little watery secretion; the cornea was less 
opaque, with fine peripheral vascularisation." 'Treatment was then stopped.

The left eye showed intense blistering of the upper lid, and the cornea was hazier than that of the right eye. After 48 hours the blistering was still marked in the upper lid. Staining was present over a good deal of the superficial area. After 72 hours there was contraction of the third lid and formation of adhesions; the cornea was slightly hazy. On the fifth day the third lid was becoming fibrotic and blistering was still apparent; the cornea was densely hazy and the iris pattern could just be seen in places. Treatment was changed to merthiolate with diffusing factor and cod liver oil. On the twelfth day the redness of the lids was much reduced; there was some mucopurulent discharge. On the sixteenth day the cornea was densely hazy, having an appearance similar to that of the right eye of rabbit No. 11. The tissues were weakened and bulged, and there was a "sago" effect over the whole upper section.

Rabbit No. 14 followed much the same course as that noted in rabbit No. 13. The cornea of the right eye began to clear on the twelfth day, and there was also less discharge and less scarring. The left eye showed definite corneal changes, very slight blepharitis and much mucoid discharge. On the sixteenth day both eyes showed characteristic corneal scarring. The animal was destroyed and the eyes retained for sectioning.

The three white rabbits of this group were all irrigated with sodium bicarbonate 2 per cent. so as to form a background for the oils No. 1,2 and 3 .

Rabbit No. 15.-The right eye, at 96 hours, showed no indications of blepharitis or mucopurulent discharge, and the third lid was healthy and active. The cornea was definitely hazy. After eleven days the lids were healthy and the cornea very slightly hazy.

The left eye, at 96 hours, was closed; there was conjunctivitis, mucopurulent discharge, lid contractions and a fine generalised keratitis. On the twelfth day the cornea was hazy and there was fine marginal staining over a large area; upper lid contractions were forming.

Rabbit No. 16.-The right eye was one-quarter open after 72 hours; there was slight mucous discharge-no definite contraction of lids. There was a general corneal haze and fine staining was present in the central area in discrete, fine dots. After ten days there was very slight blepharitis and a faint corneal opacity; the conjunctiva was healthy.

The left eye was almost fully open after 72 hours and there was no lid contraction. There was localised staining of the cornea, 
confined to the area of application of the mustard. On the tenth day a rather marked mucoid discharge was present; corneal haze was slight, but greater than in the right eye. Six fine white superficial dots could be seen.

Rabbit No. 17.- The right eye, after 72 hours, was one-third open; there was mucopurulent discharge and slight contraction of upper lid, with blistering of lower lid. The pupil was small. On the tenth day the eye was closed and there was a mucoid discharge. However, the cornea presented only an almost imperceptible haze.

The left eye exhibited rather greater mucoid discharge than the right eye, with a slight degree of lid contraction. The cornea was hazy and there was a moderate staining area. After ten days only a slight mucoid discharge was present, and there was an extremely fine keratitic haze on the cornea.

Rabbit No. 18 was the control rabbit (referred to on page 71) which was employed to examine the chemical interaction between liquid mustard and the tissues of the eye.

\section{The Ascorbic Acid Treatment Group}

This group consisted of five rabbits of which four (one white and three brindle) received injections for six days of $500 \mathrm{mgms}$. of ascorbic acid, the first injection being given twenty minutes before the application of a drop of mustard. The fifth rabbit (brindle) acted as a control, having the same exposure and treatment but without receiving ascorbic acid injections. Five minutes after exposure to mustard the right eyes of all rabbits were irrigated with sodium bicarbonate 2 per cent., and cod liver oil drops were applied. Treatment was repeated twice daily. No external treatment was given to the left eyes.

The following description of progress presents a characteristic picture of the ascorbic acid group; therefore a detailed account of each rabbit is omitted.

Rabbit No. 19.-The right eye was half open after 20 hours. There was no discharge, only slight congestion of the conjunctiva and slight blistering of the lower lid. There was a staining area on the cornea between 9 and 11 o'clock, some oedema of the cornea with fine elevations over the centre; slight superficial keratitis around the original seat of injury. After 92 hours the eye was open; there was no blepharitis, and the lids and conjunctivae appeared perfectly normal. There was very fine staining about 2 o'clock-otherwise nothing to note. On the seventh day the eye appeared perfectly healthy and the lids were unaffected. When, on the eleventh day the eye was wide open and healthy, there was a very small vascular loop on the cornea near the point 


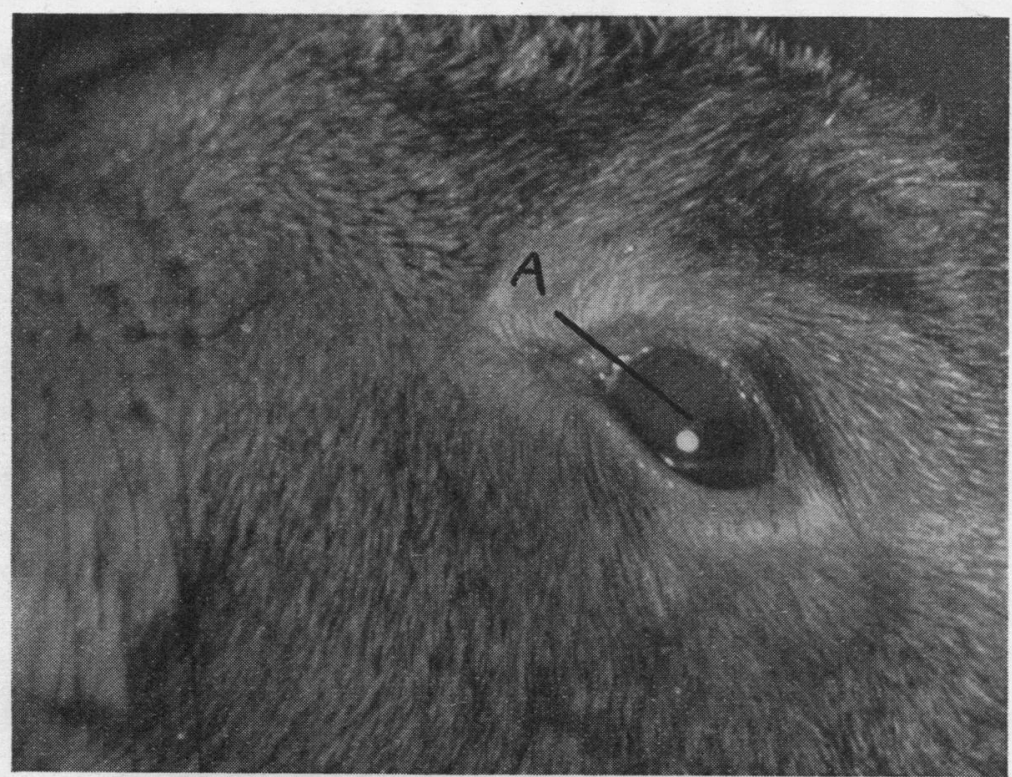

RabBit No. 19 (Ascorbic Acid Group).

Left eye photographed on the 9th day, having had no local treatment. The cornea is clear except for a very fine linear mark $(a)$ just above the light reflex. There is no discharge, no lid contraction and no conjunctival changes.

of application of the mustard. There was no inflammatory change and no appreciable corneal change. Treatment was stopped.

The left eye was one-quarter open after 20 hours, with very slight mucoid discharge. There was blistering in the upper and lower lids, and in the case of the upper lid it extended over most of the surface. There was a slight staining area about 11 o'clock, a small degree of superficial corneal oedema, and very mild keratitis. After 92 hours the eye was half open, with slight discharge and matting on inner surface of upper and lower lids-chiefly the upper lid; also, a very fine corneal haze. On the seventh day there was some contraction of the third lid, some scarring of upper and lower lids, slight conjunctivitis, and very faint corneal haze. On the eleventh day the eye was wide open; the lids were slightly red. There was no appreciable corneal haze.

With only small variations, such as the presence of pigment on the cornea of rabbit No. 20, the course of recovery of the other three rabbits receiving ascorbic acid and external treatment was identical, and characterised by mild reactions without secondary complications. The presence of pigment in the corneal wound had been noted in one or two other cases, and it was found that 
this arose from the deposit of pigment from a very fine layer of this substance which traces the inner margin of the third lid of rabbits.

On the other hand, the control rabbit, No. 23, went through the three phases of severe contamination. Notes of the right eye

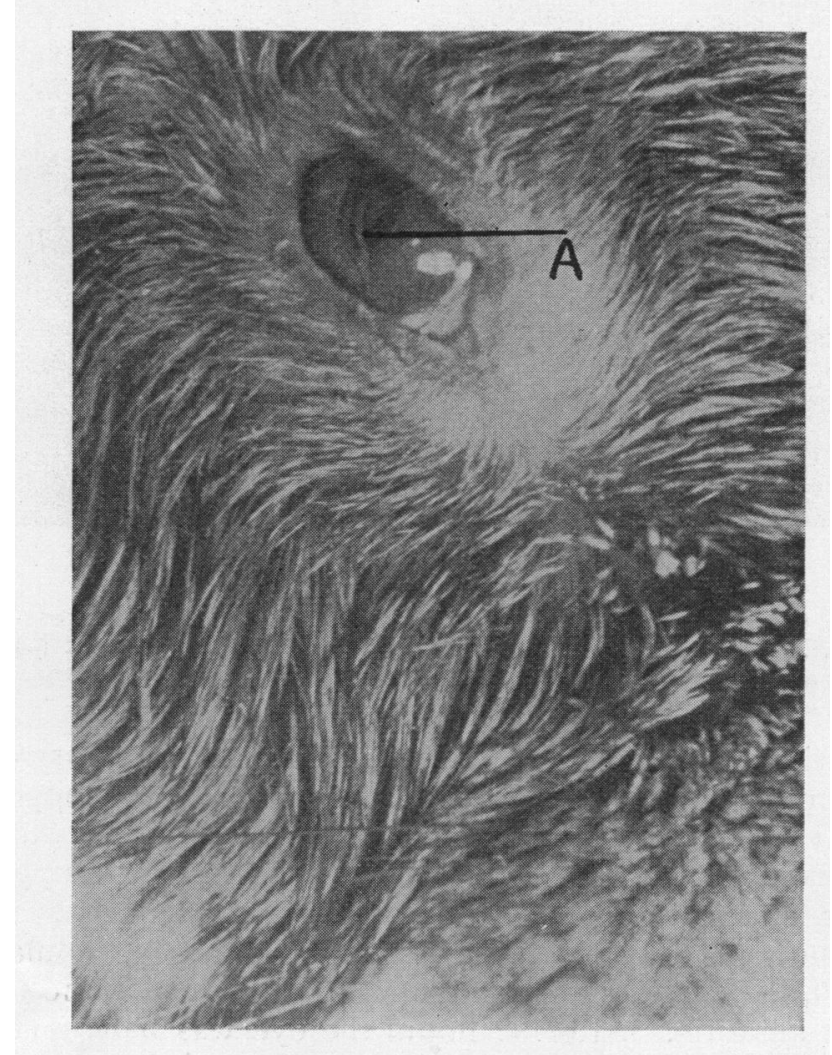

RabBIT No. 23 (Control rabbit of the Ascorbic Acid Group). Right eye photographed on the 6th day, having been treated with sodium bicarbonate and cod liver oil from the start. There is a large band of keratitis $(a)$ extending from above downwards, with an upper projection of irregular shape occupying the centre of the cornea. There is some blepharitis in the lower lid.

on the eighth day described marked mucopurulent discharge, thickening of inner lid and dense corneal haze on the upper third. At the same time the left eye showed typical deep keratitis.

In the rabbits that received ascorbic acid there appeared little difference between the right eyes having irrigation and applications of cod liver oil twice daily, and the left eyes, which did not 
receive local treatment. In one case, however, lavage and cod liver oil did appear to advance the rapidity of recovery.

The comparison between these four rabbits and the fifth of the group, was quite the most impressive feature of our study. Professor Sir A. Frederick Banting who visited the department, was particularly interested in the ascorbic acid group, and the apparently powerful influence of ascorbic acid on tissues subjected to the usually devastating action of mustard gas in drop form.

\section{Histological Report}

Taken from the left eye of rabbit No. 11 and the right eye of rabbit No. 12 .

The effects are most marked in the epithelium and become less as we go deeper.

The epithelium.-In the early stages the cells undergo cloudy swelling with chromatolysis of their nuclei. The spaces between the cells become better marked. The more superficial cells are desquamated, leaving the basal layer standing for a time as a palisade of swollen, columnar cells with definite spaces between them. Finally, these also tend to be shed. Where healing has set in the epithelium grows over from the uninjured cells and covers the denuded area. This new epithelium forms a layer thinner than normal; the cells are all flattened, there being no columnar area.

Bowman's membrane is much less well defined in the rabbit than in the human and the changes are like those of the stroma.

The stroma.-The lamellae undergo cloudy swelling, so that in the affected area the cornea is much thicker than normal. The corneal corpuscles also undergo cloudy swelling with chromatolysis of their nuclei. Later the nuclei appear to fragment, appearing as small, dark, often rounded balls. Later still they appear to multiply so that the stroma becomes much more cellular than normal. Quite early there is a marked invasion of the affected area by eosinophile cells which can be seen leaving the engorged vessels at the limbus.

Descemet's membrane.-No definite change could be seen in Descemet's membrane, but in severe cases the endothelium became swollen and, in part, desquamated.

The anterior chamber.- In severe cases an albuminous exudate appeared in the anterior chamber, but in those cases in which the eye was not too badly damaged it disappeared later.

\section{An Irrigating Speculum}

The special irrigating speculum, made by Down Brothers, consists essentially of three arms. The upper and lower arms are designed to pass beneath upper and lower lids, much as does the 
ordinary speculum but to a greater extent. The effect upon the lids is to render them about one-third open, so that the cornea is exposed and well clear of the lid margins, while the conjunctival folds and bulbar conjunctiva are not much in evidence. The idea behind this is to create a partial opening of the eye without undue pressure, and without locking off any areas which require to be subjected to the influence of lotions. This permits a retraction which, although uncomfortable without a local anaesthetic, can nevertheless be tolerated. When an anaesthetic is employed only a minimum quantity is required-for example, procaine 2 per cent . novocaine 2 to 4 per cent., cocaine 2 per cent. ( 2 drops). In view of the fact that during treatment the cornea is kept continually moist there is no contraindication to a minimal quantity of cocaine. The third arm of the speculum is curved to lie over the centre of the cornea. It cannot touch the corneal surface either during

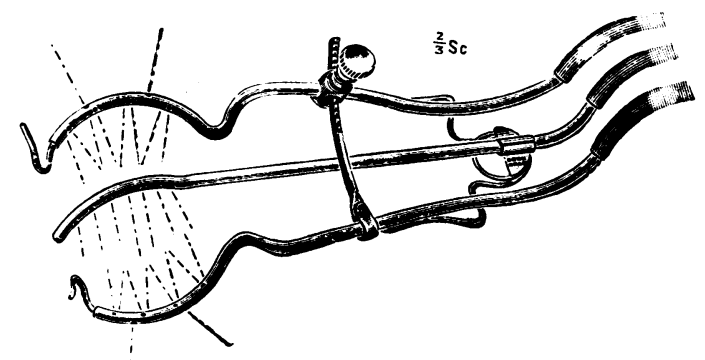

insertion, or on spontaneous movement of the patient. It can be rotated away from the cornea during insertion, although this is not necessary.

All three arms are perforated at two angles by holes of graduated size, the small holes being nearest to the source of lotion, while those farthest away are larger, so that they can receive their share of fluid. The three arms are connected by fine rubber tubing to a combined metal pipe, which in turn, is attached by further tubing to a reservoir containing a litre or more of lotion. The same lotion may be used along all three arms of the speculum; or a stronger lotion such as, merthiolate $1: 10,000$ or biniodide of mercury $1: 10,000$ can be used along the arms which pass under the lids, while saline, glucose solution, or very finely divided vitamin charged oils, may be permitted to flow over the cornea through the third arm from a separate source. The corneal counter stream prevents the streams from under the lids from reaching the corneal surface, so that retained toxic products within the oedematous conjunctival folds pass harmlessly along the partially retracted lid margins. A specially designed trough, attached to the face, drains the solution away through rubber 
tubing into a bowl. Thus the case can be left lying flat, and being irrigated continuously for many minutes. Practical trial at the Royal Air Force Hospital, Halton, has demonstrated that this procedure can be carried out successfully in cases of industrial chemical injury and of acute inflammation.

\section{Conclusions}

1. In a small percentage of animals there is some degree of natural resistance which definitely offers a barrier to the effects of liquid mustard.

2. With rare exceptions, so intense and rapid is the immediate reaction, that no local treatment can be hoped for that will prove helpful at this stage. The interaction of mustard and the secretions of the eye causes an alteration which leaves the mustard inactive as such after fifteen minutes. This alteration is probably an oxidation process which occurs after the initial reaction.

3. Irrigation with lotions that have a specific destructive effect upon the mustard is not recommended. Sodium bicarbonate 2 per cent. seems to be as helpful as any lotion, and there is reason to believe that the dehydrating effect of Bonnefon's solution may have merits. The use of atropine against the irritation of the iris leading to its contraction is clearly of importance.

4. Antiseptic washes, such as merthiolate $1: 10,000$ are clearly of value and would certainly be indicated if there was secondary infection.

5. Oil drops following irrigation appear to exert a favourable effect, and cod liver oil is probably best. There may be value in an oil with a high vitamin A content, but from this investigation we are unable to give any clear ruling on the respective merits of cod liver oil with added vitamin A and cod liver oil of B.P. standard.

6. There is reason to believe that the spread of corneal ulceration in the human eye could be arrested by the use of the specially designed irrigating speculum just described.

7. Saturation of the system with ascorbic acid, given intravenously to four rabbits, proved to have a remarkable effect in preventing the spread of keratitis and the progress of lid inflammation. Although only a few animals were treated in this way, the result in each case so outstrode all others, that it is safe to conclude that this method of treatment is well worthy of trial in any case of mustard contamination of the eye. The characteristic damage observed in the control rabbit of this group and the experience with the other eighteen rabbits of the series lends weight to this argument.

The result of this investigation, which had to be carried out 
within a limited period, seems clearly to indicate that there are methods by which the effect of mustard contamination of the eye can be considerably mitigated. So far as we know, there has been no previous attempt to affect the course of mustard injury to the eye through the tissue barrier.

In the time at our disposal we were unable to investigate the period that could elapse between the injury and the administration of ascorbic acid. This, and the level of effective dosage must be subjects of further investigation. In the present investigation we used a very high dosage of ascorbic acid.

It is probable that there are substances other than ascorbic acid, cheaper and more readily available, that might exert a similar effect. This also calls for future study.

Since the completion of this work some further investigations have been undertaken with the object of discovering whether injections of ascorbic acid up to two hours after mustard injury and at the lower dosage level of $100 \mathrm{mg}$. is capable of controlling the corneal invasion. Examinations of animals thus exposed and treated proves that this is so.

At the same time some experiments were done in which sodium thiosulphate (10 per cent.)* in $500 \mathrm{mgm}$. doses intravenously was given. Examination of these cases indicates that this substance also, given in this fashion, possesses a definite value; but the results obtained from the ascorbic acid treatment are undoubtedly better. No other treatment in the form of lavage or oils was given in either of the latter series of cases.

\section{Acknowledgment}

We have to express our thanks to the Directors of Glaxo Laboratories Limited, who freely placed one of their research laboratories at the disposal of the Royal Air Force for this work.

We wish also to acknowledge the assistance given by $\mathrm{Mr}$. R. M. Jenner, B.Sc., and Dr. J. Ungar in carrying out the experiments, by Mr. J. T. Marsh in taking the photographs of the external features and by Miss M. C. Lindsay in taking and collating an immense number of notes, and for her assistance in preparing this paper.

The histological examination and report was very kindly undertaken at the Royal Westminster Ophthalmic Hospital by Mr. Eugene Wolff, F.R.C.S.

* Sodium thiosulphate, $\mathrm{Na}_{2} \mathrm{~S}_{2} \mathrm{O}_{3} 5 \mathrm{H}_{2} \mathrm{O}$ is readily soluble in water. It should be stored in a closely stoppered bottle. A 10 per cent. solution can be used for injection, and it is sterilised by heat or filtration. Two grams daily and intravenously can be given with safety, and there are reports in the literature of much higher doses being given. Sodium thiosulphate can be obtained in solid form, or in ampoules for injection. 
Effects of Liguid Mustard Gas upon Eyes of Rabbits 91

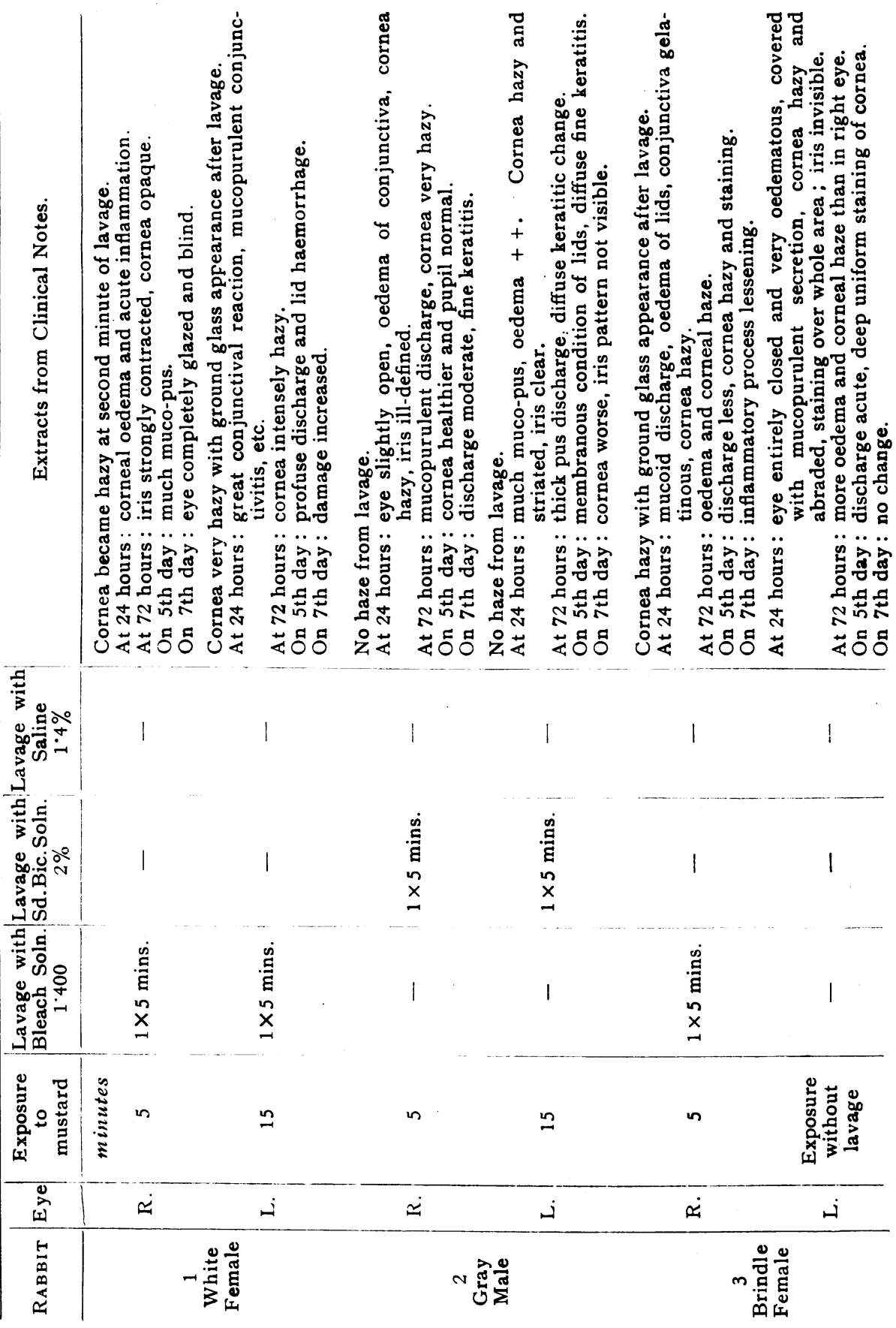


P. C. Livingston and H. M. WalkeR

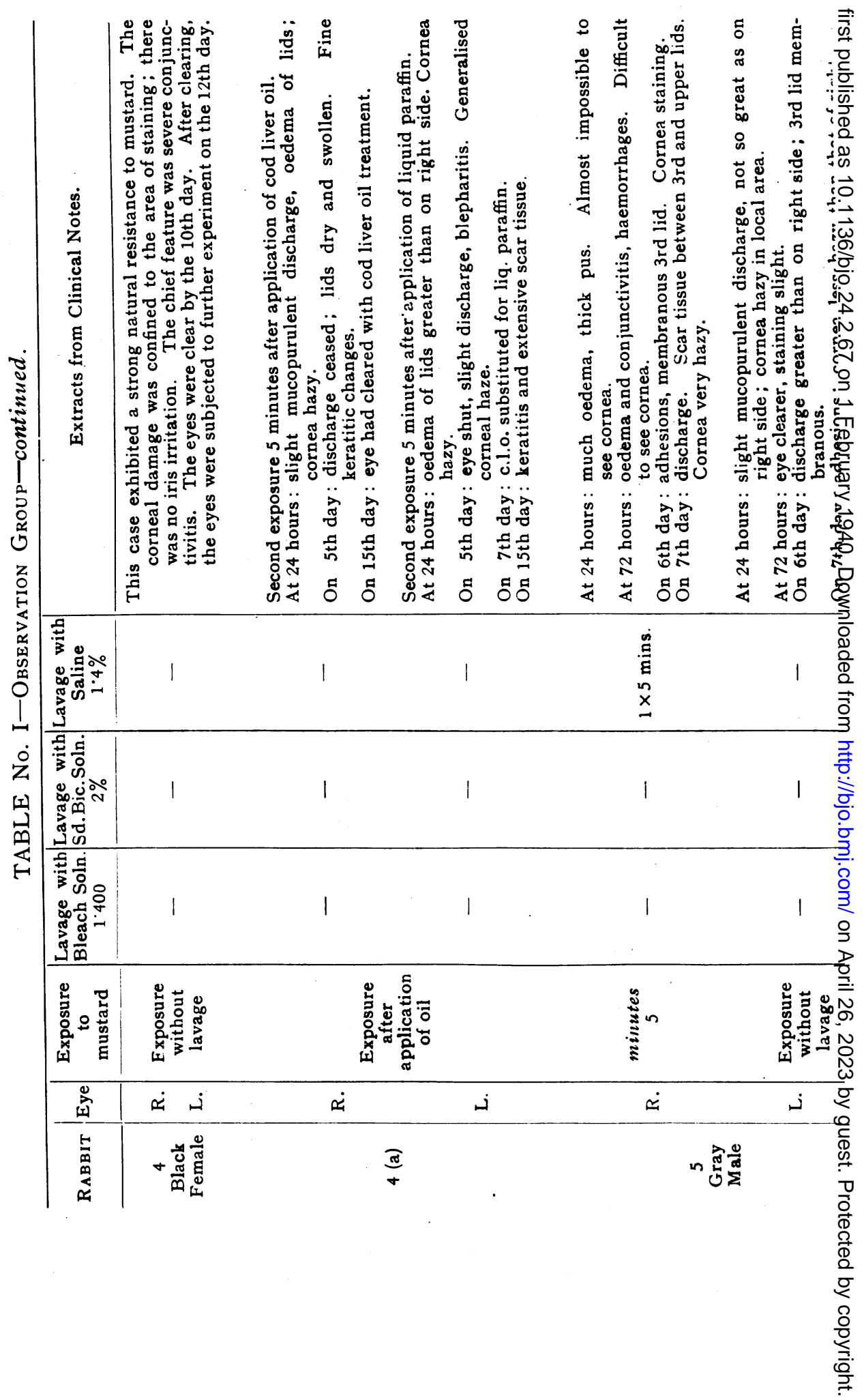


EfFects of Liquid Mustard Gas upon Eyes of Rabbits

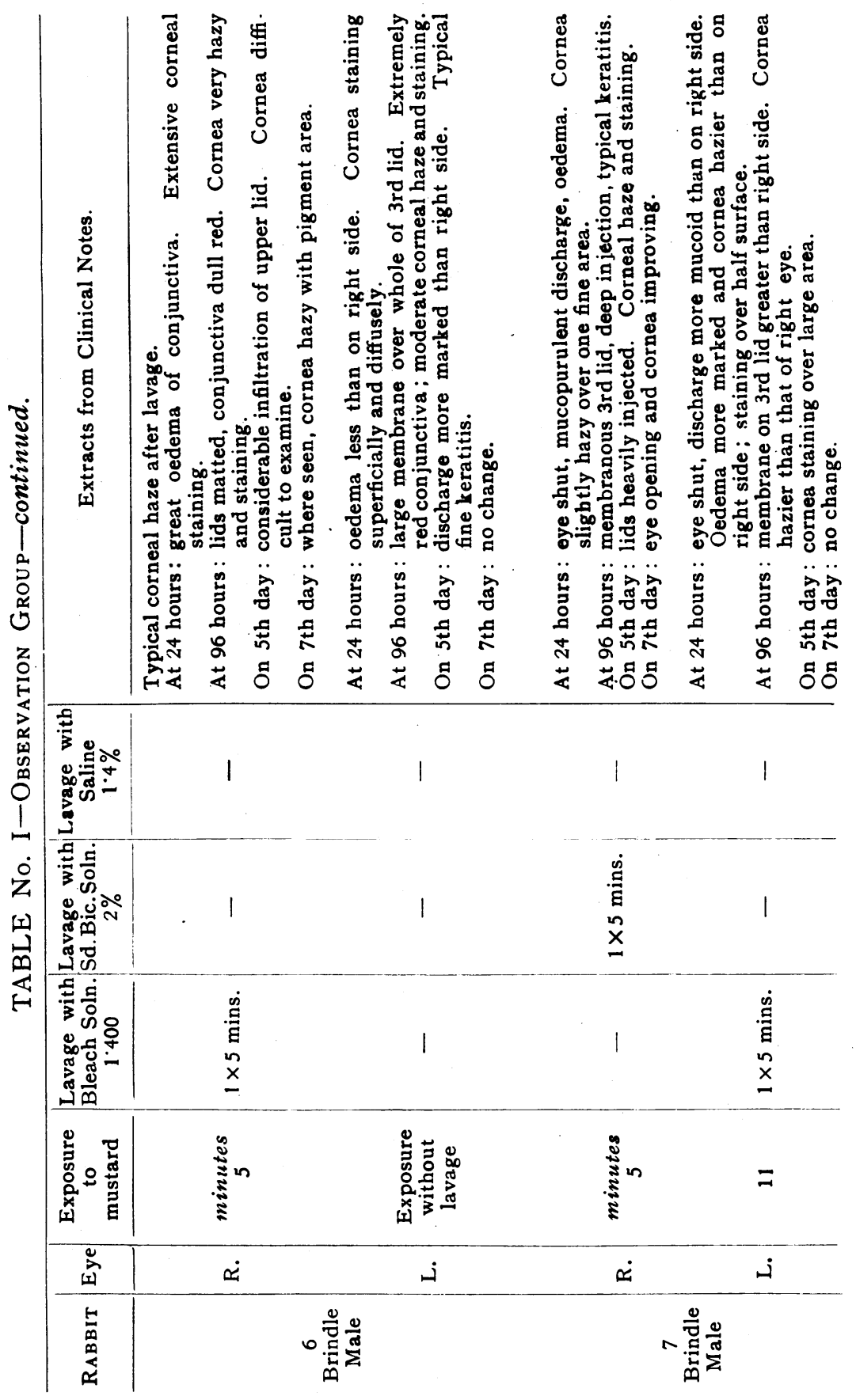




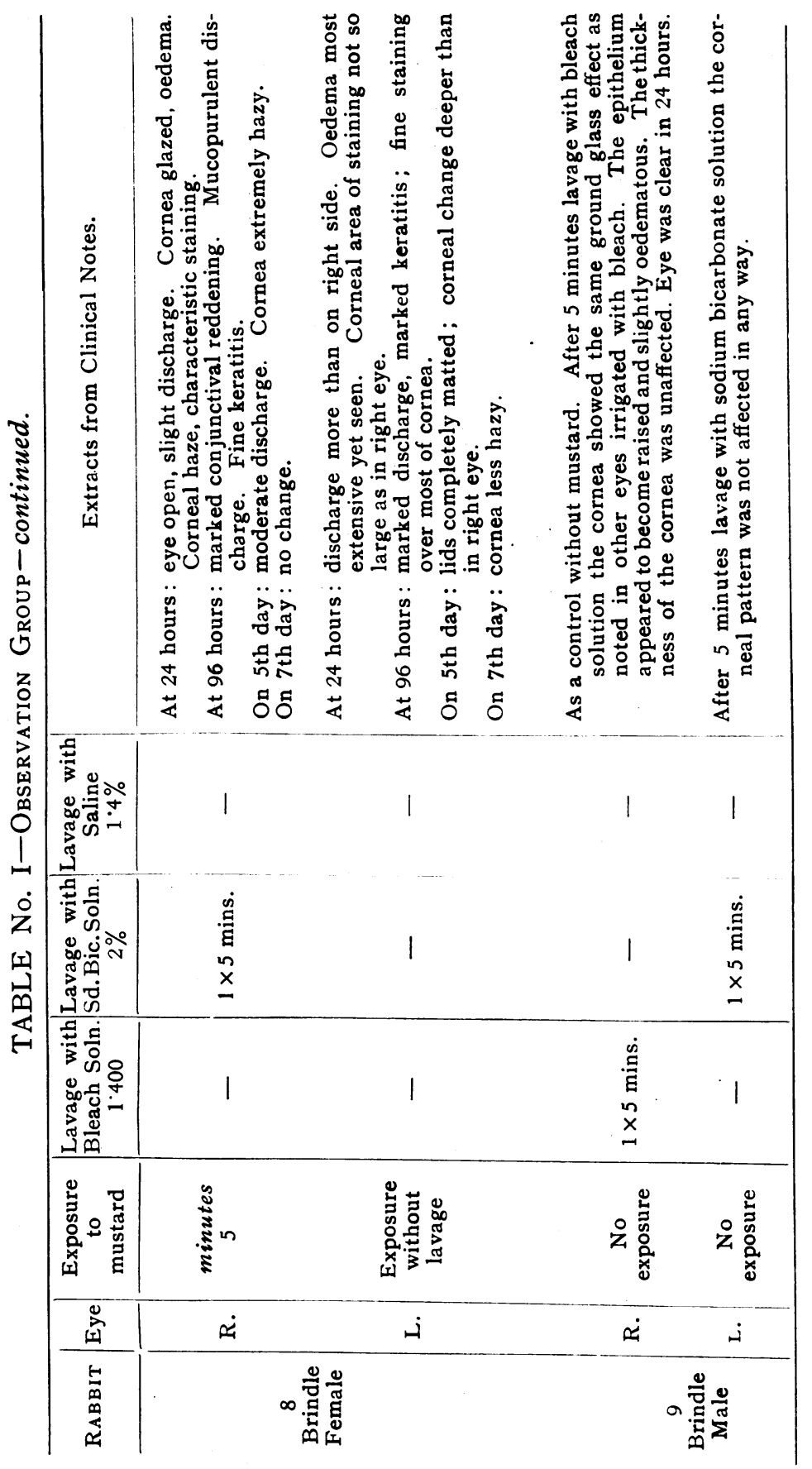


EfFects of Liquid Mustard Gas upon Eyes of Rabits 95

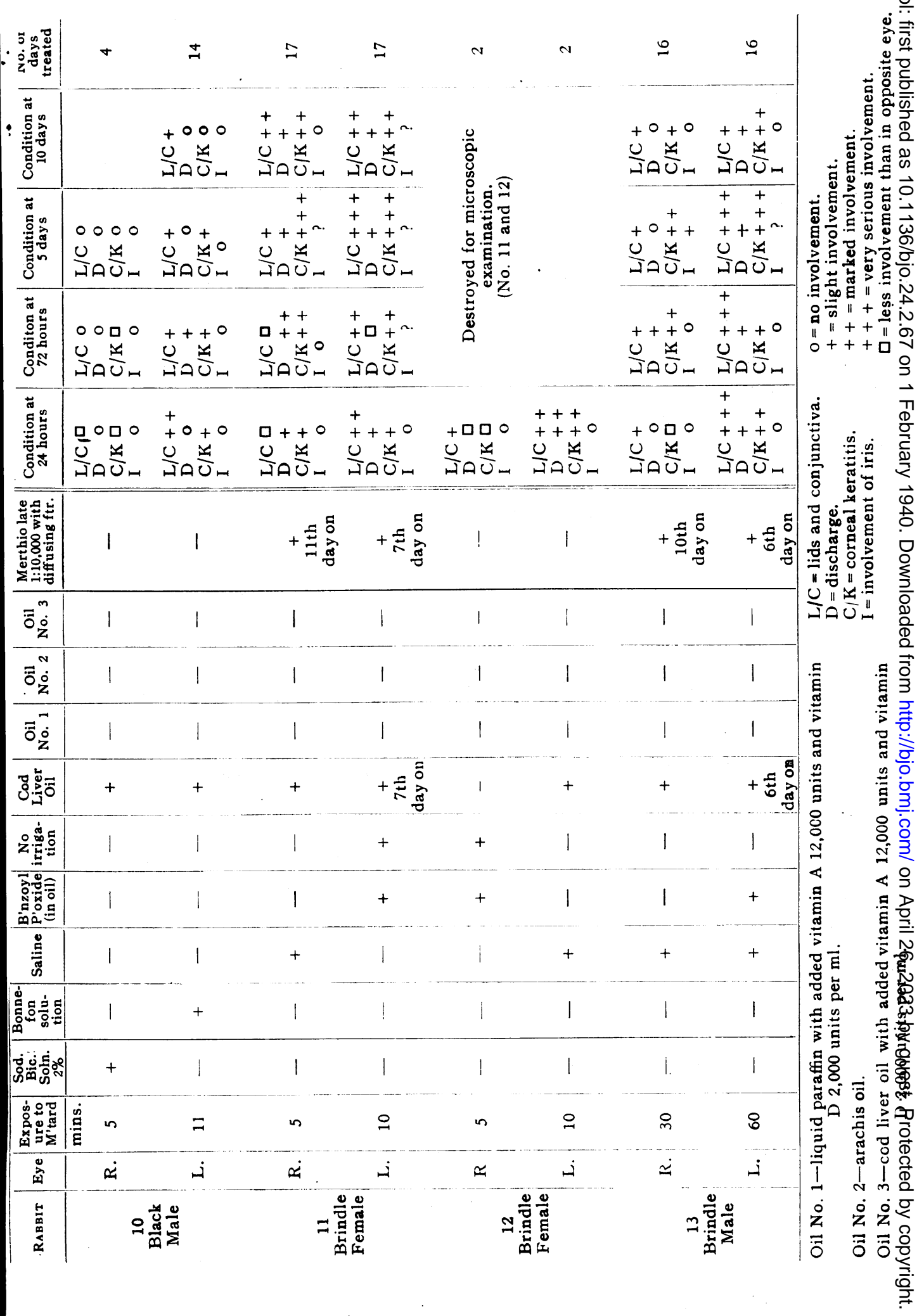




\begin{tabular}{|c|c|c|c|c|c|c|c|c|}
\hline 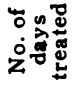 & $\approx$ & $\approx$ & $\approx$ & $\mathbb{N}$ & $=$ & $\Rightarrow$ & $\Rightarrow$ & $\Rightarrow$ \\
\hline 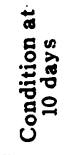 & $\begin{array}{l}0+0 \\
\text { Uै口 }\end{array}$ & $\begin{array}{l}+0+0 \\
\stackrel{0}{\mathrm{U}}+{ }^{0}\end{array}$ & 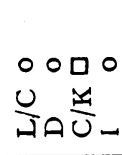 & $\begin{array}{l}+ \\
++ \\
\dot{U} \\
\text { HคU }\end{array}$ & 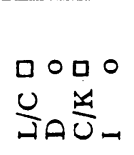 & 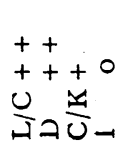 & 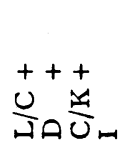 & 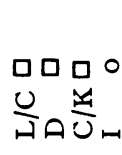 \\
\hline 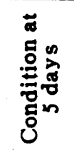 & $\begin{array}{l}+++^{\circ} \\
\text { Uั }\end{array}$ & $\begin{array}{l}+++ \\
\text { Uै口 }\end{array}$ & 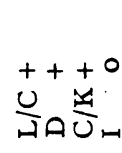 & 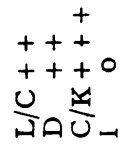 & $\begin{array}{l}++ \\
+++0 \\
\text { ॥ロ }\end{array}$ & س & 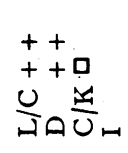 & $\begin{array}{l}++ \\
++0 \\
\text { जค }\end{array}$ \\
\hline 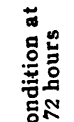 & $\begin{array}{l}+ \\
+ \\
U\end{array}$ & $\begin{array}{l}+ \\
\dot{u}\end{array}$ & $\begin{array}{l}+ \\
00+0 \\
0\end{array}$ & $\begin{array}{l}+ \\
+ \\
\text { U }\end{array}$ & $\stackrel{++}{+}{ }^{+}$ & ० & $\begin{array}{c}+ \\
++\square \\
0\end{array}$ & \begin{tabular}{l}
+ \\
$+\square+0$ \\
\multirow{2}{*}{+0}
\end{tabular} \\
\hline
\end{tabular}

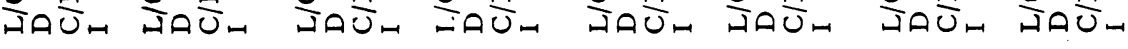

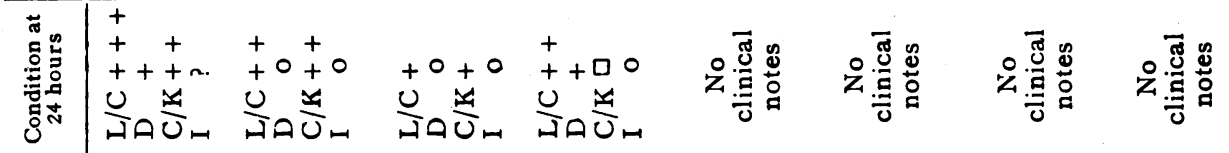

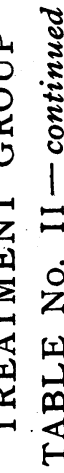

乙。

$$
\text { 商 }
$$

के:

.

品

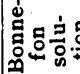

ต่ํำ

\begin{tabular}{|c|c|c|c|c|c|c|c|c|}
\hline 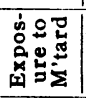 & $\stackrel{g}{g}$ & 8 & 0 & $\cong$ & in & 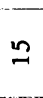 & in & 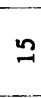 \\
\hline 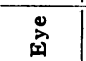 & ن & نـ & نَ & نـ & نم & ఉ & نه & نهر \\
\hline 志 & & & & & & & & \\
\hline
\end{tabular}


TABLE No. III-Ascorbic Acid Group

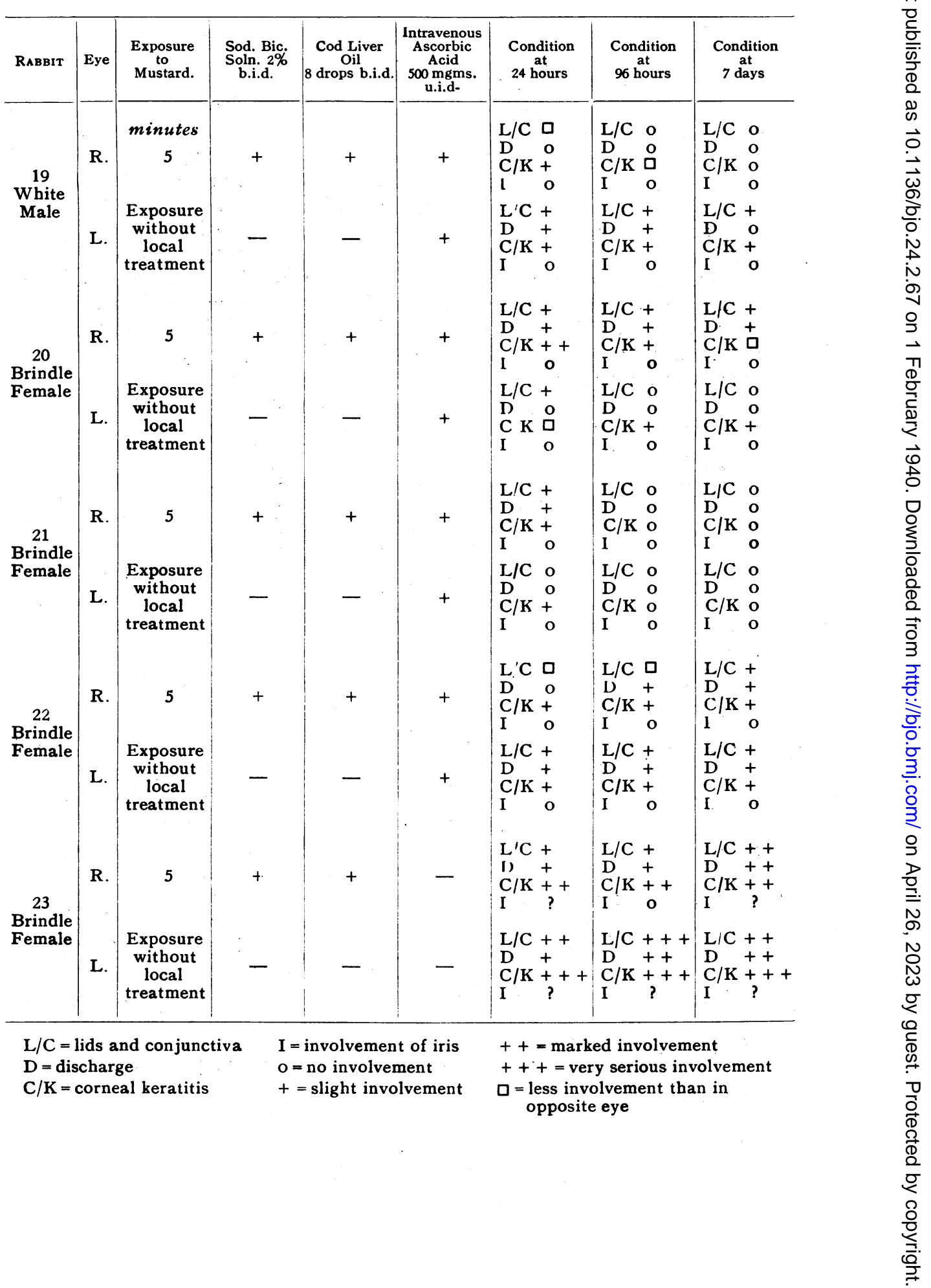

